J. Clin. Chem. Clin. Biochem.

Vol. 17, 1979, pp. 369-372

\title{
Vorbehandlung von Heparin-Plasma zur Protein-Elektrophorese mit Reptilase
}

\author{
Von D. Heimann, $V$. Wolf und $H$. Keller \\ Institut für Klinische Chemie und Haematologie des Kantons St. Gallen
}

(Eingegangen am 8. November 1978/8. Januar 1979)

\begin{abstract}
Zusammenfassung: Aus Heparin-Plasma kann mittels Reptilase (Batroxobin) die Fibrinogenfraktion quantitativ ausgefällt werden. Wird vom Ubberstand eine elektrophoretische Trennung der Proteine auf Cellulose-Acetat-Folien durchgeführt, so ist das Ergebnis qualitativ und quantitativ nahezu identisch mit dem des entsprechenden Serums. Diese Präparationstechnik kann auch angewandt werden, um einen Fibrinogengradienten (verursacht durch Antikoagulantientherapie) von einem Myelomgradienten zu unterscheiden.
\end{abstract}

\section{The use of Reptilase for electrophoresis of heparinized plasma}

Summary: Fibrinogen can be precipitated from Heparin-plasma by Reptilase (Batroxobin). The electrophoretic pattern of the supernatant on cellulose acetate is nearly identical with that of the corresponding serum. This technique is also useful in differentiating a gradient of fibrinogen (caused by effects of anticoagulants) from a myeloma peak.

\section{Einfuihrung}

Der Einsatz von Heparin-Plasma an Stelle von Serum im Bereich der klinisch-chemischen Routineanalytik hat viele Vorteile $(1,2)$. Heparin-Plasma eignet sich jedoch für einige analytische Verfahren, z. B. für die ProteinElektrophorese auf Cellulose-Acetat-Folien, nicht als Ausgangsmaterial. Die Trennnạhigkeit der üblichen Systeme reicht nicht aus, um Fibrinogen als eigene Fraktion, abgetrennt von den anderen Fraktionen, darzustellen. Es erscheint im kathodischen Bereich der $\beta$-GlobulinFraktion als relativ breiter Gradient. In gleicher Pósition werden aber auch Paraproteingrạdienten mit den Antigendeterminanten vom Typ IgA oder IgM gelegentlich beobachtet, die von Fibrinogengradienten visuell nicht zu unterscheiden sind.

Die Elektrophorese von Fibrinogen-haltigen Proben wird in der einschlägigen Literatur nicht diskutiert $(3,4)$, obwohl immer wieder irrtümlich Plasma oder Plasma-enthaltendes. Serum einer Elektrophorese unterzogen wird. Der häufige therapeutische Einșatz von Heparing, Dicumarolpräparaten und anderen Antikoagulantien führt zwangsläufig dazu, dạ nicht oder nicht vollständig geronnenes Mäterial elektrophoretisch getrennt wird, da es dem Aspekt nach Serum entspricht. Der dann auftretende Gradient muß mit Hilfe immunologischer Verfahren identifiziert werden, die einen erheblichen Aufwand an Zeit und teurem Material beanspruchen. Andererseits wäre es aus organisatorischen Gründen in allen Laboratorien, die Heparin-Plasma als Untersuchungsmaterial verwenden, günstig, wenn das gleiche Material auch für die Protein-Elektrophorese eingesetzt werden könnte. Durch Batroxobin (5) kann bekanntlich Fibrinogen auch aus Heparinplasma rasch und spezifisch ausgefällt werden. Nach Abzentrifugieren ist der Uberstand für die Protein-Elektrophorese gut geeignet.

\section{Methodik}

Von 120 nicht selektionierten Patienten des Kantonsspitals St. Gallen wurde bei einer Venenpunktion Heparinblut $(0,2 \mathrm{~g} / 1$ Ammoniumheparinat) und Nativblut entnommen. Das Heparinblut wurde in der ersten Stunde nach der Blutentnahme bei $3000 \mathrm{~g}$ abzentrifugierf und das überstehende Heparin-Plasma abgetrënnt.

Das Nativblut verblieb zur Gerinnung 2 Stunden bei Raumtemperatur in Glasgefäßen. Nach Abzentrifugieren wurde das überstehende Serum abgetrennt.

Vom Heparin-Plasma wurden $250 \mu 1$ mit $25 \mu l$ Reptilasereagens (Boehringer Mannheim, Nummer 126560) in einem Mikrolitergefäß $5 \mathrm{~min}$ bei $37^{\circ} \mathrm{C}$ inkubiert und anschließend das Präzipitat während $10 \mathrm{~min}$ bei $10000 \mathrm{~g}$ abzentrifugiert. Für die vergleichenden Untersuchungen wurde jeweils von jedem $\mathrm{Pa}$ tienten die elektrophoretische Trennung dreifach parallel durchgefuihrt:

a) vom Heparin-Plasma

b) vom Heparin-Plasma nach Ausfällung des Fibrinogens mittels Reptilase

c) vom zugehörigen Serum. 
Die Cellulose-Acetat-Folien-Elektrophorese erfolgte in der üblichen Form (6), wobei mit Amidoschwarz 10 B-Lösung (Merck, Artikel-Nummer 1156) angefärbt wurde.

\section{Ergebnisse}

Die visuelle Inspektion zeigte jeweils bei den Plasmatrennungen einen mehr oder minder deutlichen Fibrinogengradienten, Reptilase-Plasma oder Serum ließen keinen Unterschied erkennen. Gleiche Ergebnisse brachte auch die densitometrische Auswertung und Aufzeichnung durch einen Analogschreiber:
Die Abbildung 1 zeigt eine normale ElektrophoreseCharakteristik von Plasma, Reptilase-Plasma und Serum. Der Fibrinogengradient zwischen $\beta$ - und $\boldsymbol{\gamma}$-GlobulinFraktion verschwindet nach der Reptilasebehandlung. Die Charakteristik ist kaum von der des Serums zu unterscheiden.

Das gleiche gilt für eine Probe mit relativ hoher $\alpha_{1}$ und $\alpha_{2}$-Globulin-Fraktion (Abb. 2).

Bei einer polyklonalen Gammopathie aufgrund einer Lebercirrhose ist der Fibrinogengradient im Plasma nur noch schwach zu erkennen (Abb. 3). Nach Behandlung mit Reptilase ist der kleine Gradient eliminiert.
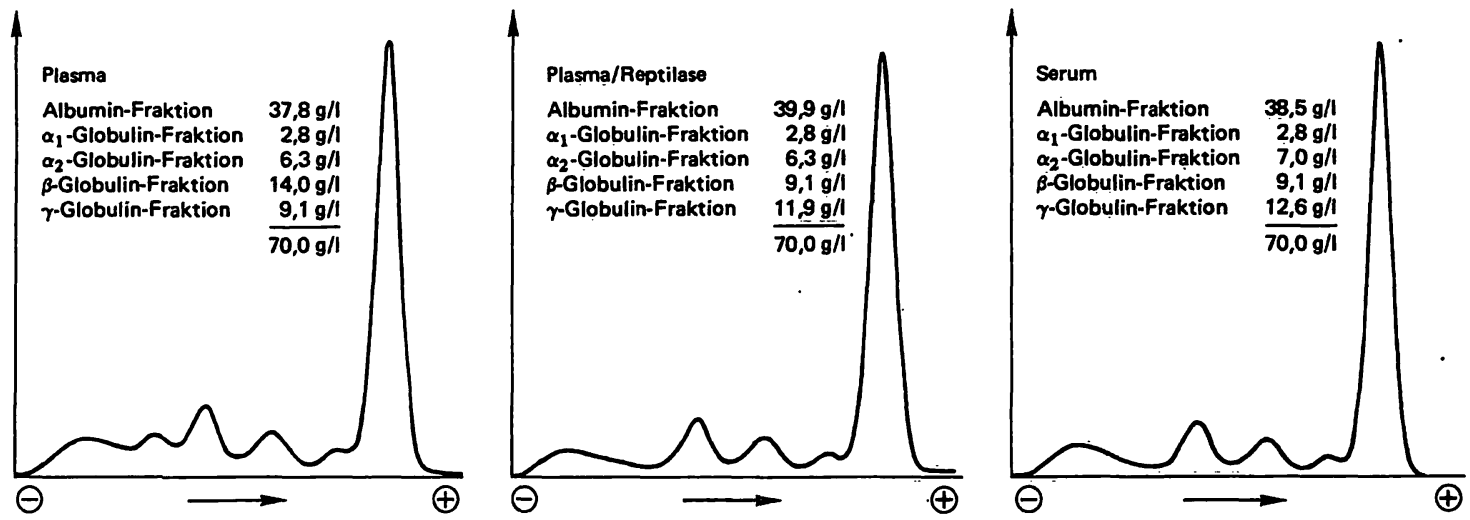

Abb. 1. Plasma vor und nach Reptilase-Behandlung und entsprechendes Serum eines Patienten ohne Veränderung des SerumeiweißMusters. Die Berechnung der Proteinfraktionen erfolgte nach Abzug des Fibrinogenanteils.
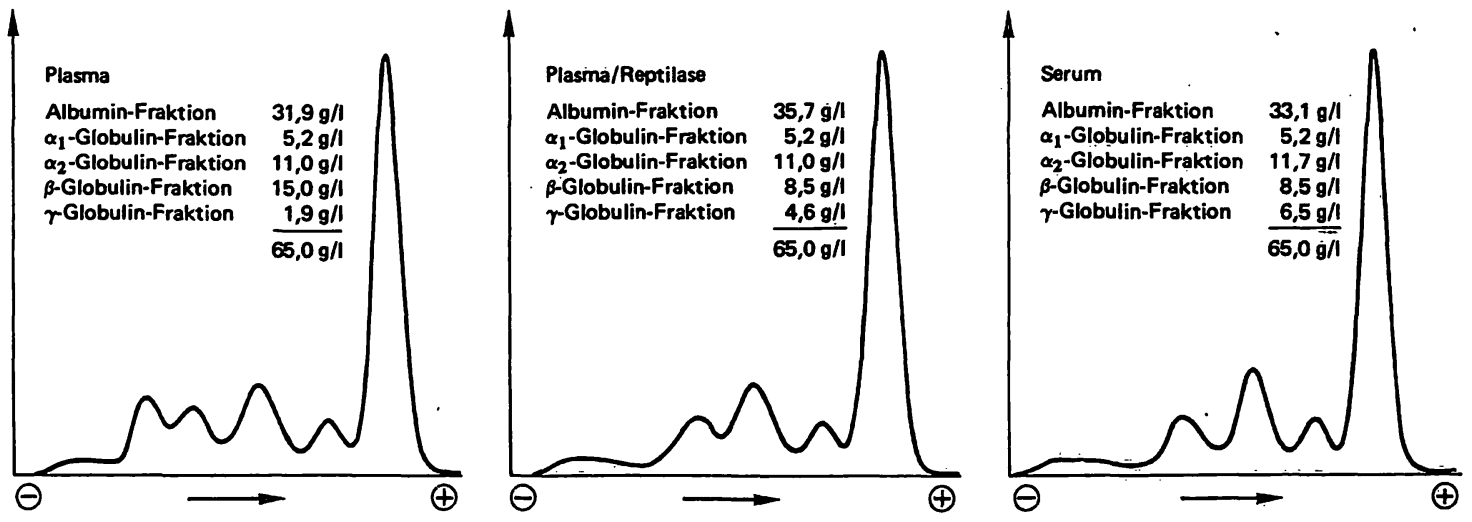

Abb. 2. Plasma vor und nach Reptilase-Behandlung und entsprechendes Serum eines Patienten mit einer Hypalbuminaemie und Vermehrung der schnell wandernden Globulinfraktionen.
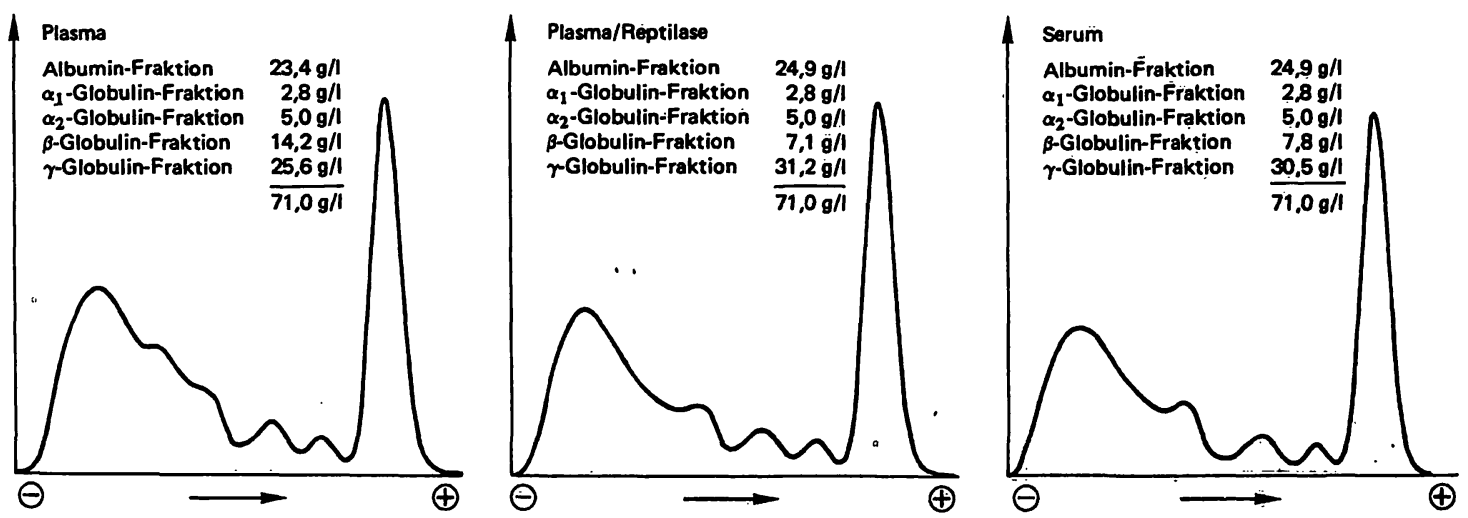

Abb. 3. Plasma vor und nach Reptilase-Behandlung und entsprechendes Serum eines Patienten mit einer Hypalbuminaemie und massiver Vermehrung langsam wandernder Globulinfraktionen aufgrund einer Lebercirrhose. 

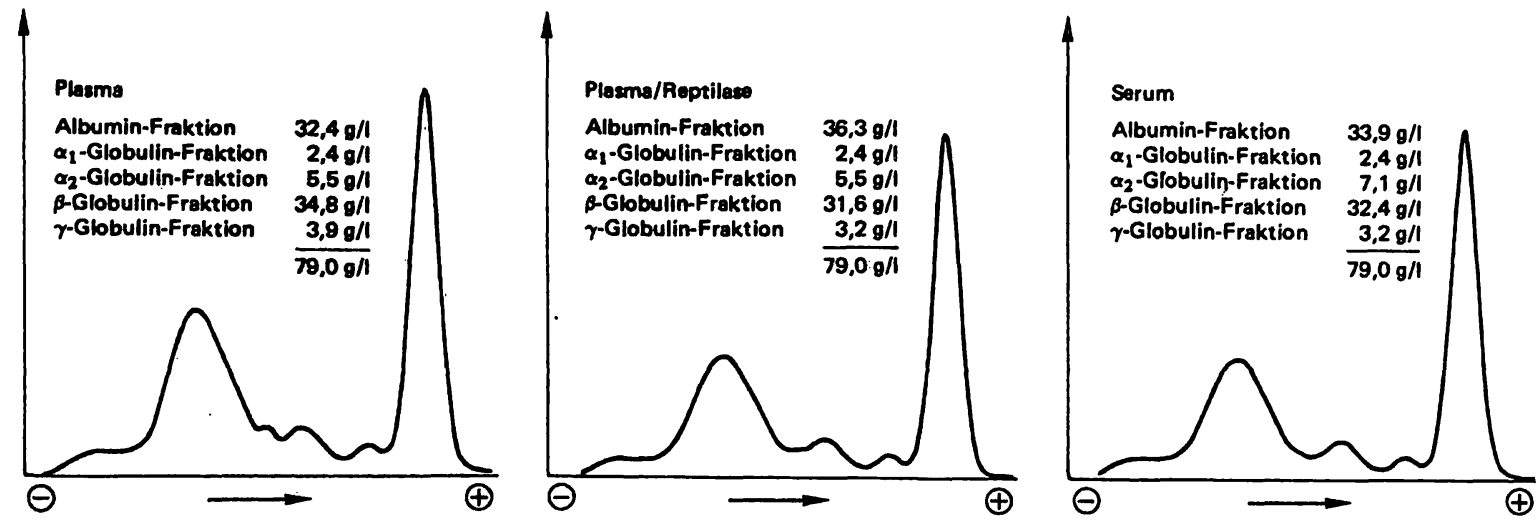

Abb. 4. Plasma vor und nach Reptilase-Behandlung und entsprechendes Serum eines Patienten mit einer Paraproteinaemie mit den Antigendeterminanten vom Typ IgA Kappa.

Monoklonale Gammopathien werden durch Reptilasebehandlung nicht verändert, wie die Abbildung 4 deutlich zeigt. Auch bei dieser Konstellation (monoklonale Gammopathie mit den Antigendeterminanten vom Typ IgA Kappa) ist der relativ kleine Fibrinogengradient in der Plasmaprobe noch sichtbar, Reptilase-Plasma und Serum sind praktisch identisch.

Ähnliches gilt für andere monoklonale Gammopathien, die wir untersuchen konnten. In keinem Fall wurde der Anteil des Paraproteins durch die Reptilasebehandlung qualitativ oder quantitativ verändert.

Bei den vergleichenden Untersuchungen an 120 Proben wurden die Differenzen zwischen Serum und ReptilasePlasma für die densitometrisch ausgewerteten Diạgramme errechnet (Tab. 1). Der Median des Albuminanteils lag beim Serum bei 0,542, beim Reptilase-Plasma bei 0,565. Die Differenzen für die fünf Fraktionen sind in der Tabelle wiedergegeben. Der relativ breite $95 \%$-Bereich rührt daher, daß die Proben von hospitalisierten Pạtienten - nicht von Gesunden - stammten. Zusammenfassend geht aus der Tabelle hervor, daß die

Tab. 1. Die an 120 Patientenproben ermittelten Differenzen zwischen Serum und Reptilase-Plasma, näheres siehe Text.

Differenzen Serum-Reptilase-Plasmạa (120 Patienten-Proben)

\begin{tabular}{lcc}
\hline & Median in g/l & 95 Perzentile \\
\hline Albiumin-Fraktion & $-0,998$ & $-3,45+2,08$ \\
$\alpha_{1}$-Globulin-Fraktion & $+0,015$ & $-0,04+0,07$ \\
$\alpha_{2}$-Globulin-Fraktion & $-0,024$ & $-0,02+0,02$ \\
$\beta$-Globulin-Fraktion & $+0,085$ & $-0,28+0,47$ \\
$\gamma$-Globulin-Fraktion & $+0,143$ & $-0,31+0,61$ \\
\hline
\end{tabular}

Albuminfraktion im Serum im Mittel gering niedriger, die $\beta$ - und $\gamma$-Globulin-Fraktion dagegen leicht höher gemessen wurden als im Reptilase-Plasma. Die Elektrophorese-Charakteristik zwischen Serum und ReptilasePlasma war in allen 120 Fällen praktisch über einstimmend.

Die vorgelegten Ergebnisse zeigen, daß es grundsätzlich möglich ist, mit Hilfe von Reptilase aus Plasma ein Untersuchungsmaterial zu erhalten, das sich elektrophoretisch identisch wie Serum verhält. Daraus ergeben sich folgende Vorteile:

1. Laboratorien, die mit Heparin-Plasma als Ausgangsmaterial in der Routineanalytik arbeiten, können durch Reptilasefällung des Fibrinogens zu einem Untersuchungsmaterial gelangen, das sich auch für die Protein-Elektrophorese eignet.

2. Wenn mit Serum gearbeitet wird, so empfiehlt es sich, bei Auftreten eines suspekten Gradienten im Bereich zwischen der $\beta$ - und $\gamma$-Globulin-Fraktion die Elektrophorese zu wiederholen, nachdem das Material mit Reptilase versetzt und abzentrifugiert wurde. Verschwindet der Gradient, so handelt es sich mit Sicherheit um Fibrinogen. Bleibt der Gradient dagegen auch nach Reptilase-Behandlung unverändert, so ist die Annahme einer monoklonalen Gammopathie zulässig.

Durch Polymerisationshemmer, Fibrinspaltprodukte und Myelom-Antithrombine wird die Reptilase gehemmt. Die gewählte Inkubationszeit von $5 \mathrm{~min}$ bei $+37^{\circ} \mathrm{C}$ und die hohe Konzentration an Reptilase sind jedoch ausreichend, um das Fibrinogen auch unter ungünstigen Bedingungen quantitativ auszufällen. Deshalb haben wir auch bei den Myelom-Plasmen in keinem Fall Reste von Fibrinogen beobachten können. 


\section{Literatur}

1. Roth, M. (1974), Collection and preparation of samples in: Clinical Biochemistry Vol. I (Curtius, H. C. \& Roth, M. eds.), Verlag W. de Gruyter, Berlin.

2. Colombo, J. B. (1978), Blutentnahme in: Klinische Chemie (Richterich, R. \& Colombo, J. B. eds.), Verlag S. Karger, Basel.

3. Götz, H. (1974), Fehldeutung immunelektrophoretischer Serumbefunde in: Serumproteine (Engelhardt, A. \& Lommel, H., eds.), Verlag Chemie, Weinheim.
4. Hobbs, J. R. (1971), Adv. Clin. Chem. 14, 219-317.

5. Ubersicht bei: Stocker, K. \& Barlow, H. G. (197.6), Methods Enżymology Vol. $X L V, 214=223$.

6. Kohn, J. (1964), Ärztl. Labor, 10, 232-248; 269-278.
Prof. Dr. Dr. H. Keller İnstitut für klinische Chemie und Hämatologie des Kantons St. Gallen

Frohbergstraße 3

CH-9000 St. Gallen 